\title{
City and Terrorism: Impact of Terror on Urban Culture and the Fabric of Lahore, Pakistan
}

\author{
Hafsa Imtiaz \\ National College of Arts \\ 4, The Mall, Lahore \\ hafsaimtiaz@gmail.com
}

\begin{abstract}
Post 9/11 saw a shift in the way people behaved, used and even looked at the city of Lahore, although the transformation remained subtle and slow. Starting in 2006, Lahore saw malicious terrorist attacks which targeted government buildings, and public and religious places. "CIRCLe" reported that the attacks in Punjab account for only $18 \%$ of attacks in the whole of the country, yet in terms of deaths, Punjab is 18 percent of the casualty figure of KPK and 19 percent of the casualty figure of FATA

The past decade has impacted the physical as well as the social fabric of the city. Terrorism has given rise to an environment of insecurity in Lahore. It is rapidly reshaping not only the fabric of the city but the everyday life of the residents and the socio-economic dynamics as well. This fear can be examined by understanding how people behave, move, interact, use and reminisce public spaces. In such conditions, fear and paranoia become one of the most important tools for its people to map the city and to understand society in its true form. It becomes imperative to understand the fabric of the city within such realm. The paper aims to understand violence and terrorism forms prevailing in the city, and their evolution. Mapping of the area of Mall road is used to understand the direct impact in terms of design elements that have altered the fabric of the place and photographic survey highlights the transformation in the built environment over the years. The paper will draw conclusions in the form of changes in the built fabric and the resulting behaviour of people in the environment. This will be read as a continuous process of change in the built and social fabric of the society.
\end{abstract}

Keywords: Terror, Fear, Paranoia, City, Public Spaces, Lahore.

\section{Introduction}

Cities are the cradle of civilization and have been encompassing its growth, development and progress through its composition and fabric. From walled cities to urban centers, they have evolved with the evolution of human kind and are perfect models of human thoughts, humanity and advancement. Throughout history the cities have seen, suffered and survived natural and manmade destruction and catastrophes. This was evident in the walled cities, which required fortification and defense and later the dissolvent of these walls to facilitate the growth and evolution of the city. Where it may seem that the fortress walls (built fabric) have been eradicated but in truth over centuries these walls have transformed with the evolution of the violence in civilization. The question then arises that what is violence and what is terror? And most importantly how does it impact us? These are some fundamental questions, which will inform the research of this paper. There can be many ways to look at war and terror, and one important way 
is through not only analysing the loss of human lives, but also looking at the lives of the ones who survived. The following tables sheds some light on the impact of terrorism in Pakistan.

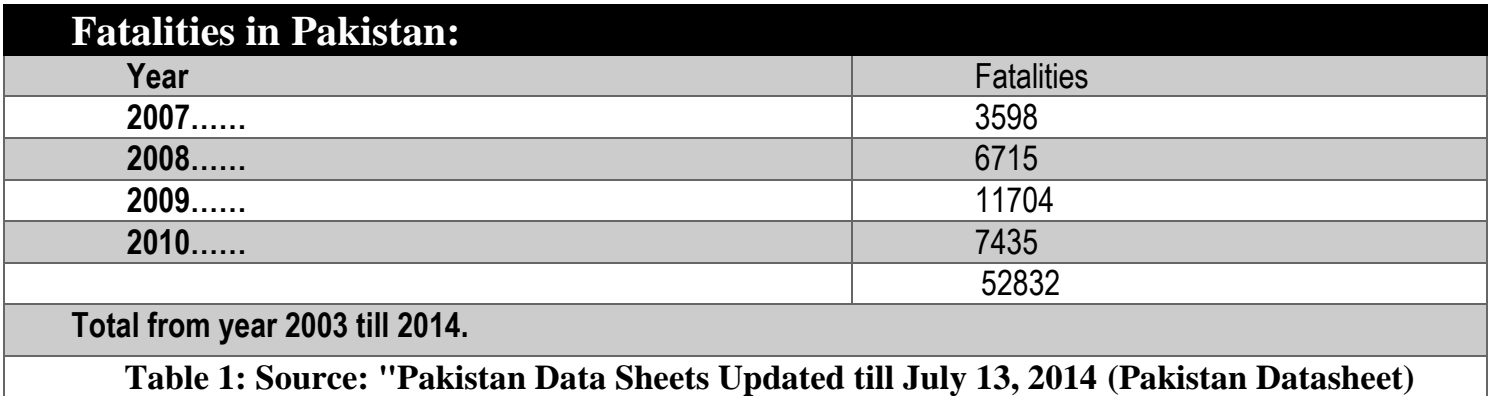

The table above sketches a horrendous tale of terror, murder and mayhem. The causalities and fatalities can be defined in numerous ways especially in the context of Pakistan. The thing to observe is the rate of increase in the fatalities over the years. The table very clearly shows the alarming increase in the fatality rate over the years. This kind of constant fear and terror leaves a lasting impression on the society in terms of built destruction (due to terror) to the fabric of the city and a psychological impact on the society in the form of behaviour pattern of movement and living trends. The paper has the following objectives:

- To mark and map the kinds of violence/terror inflicted in the (selected) parts of the city.

- To mark and map the changes in the built form due to the above mapped violence/terrorism.

- To identify changes in the social fabric of the (selected) parts of the city due to the changes in built fabric.

\section{Literature Review}

The phenomenon of new military urbanism (Graham, 2014) is not just true for western cities but can be observed in the east too. The term coined by S. Graham probably defines best the application of war in the city centers and the response of the city to counter/design for war on terror. According to Graham, "Fundamental to the new military urbanism is the paradigmatic shift that renders cities' communal and private spaces, as well as their infrastructure along with their civilian populations - a source of targets and threats." This had been evident in the years of terrorist attacks in the city center of Lahore.

To understand the relation of built fabric, its relation to violence/war and finally its impact on society, it's imperative to read this as a two-way road where each new form of violence/war creates a shift in the society and its social fabric which in turn manifests itself in the urban fabric (Crossette, 2020). It's important to point out that war being moved in the cities (instead being fought outside the walls/city periphery), infiltrating and inflicting violence from within is a new phenomenon and the studies carried out on the subject of PTS (post trauma syndrome) and its impact on the society are not extensive. On the other hand, there have been psychological studies on the impact of paranoia on society. According to research, fear and paranoia slowly penetrate in the society leaving a permanent mark in its fabric. This can be further explained through the following:

'Very little is known about the relationship of paranoia to sociodemographic variables. However, prior theory and research provide a basis for inference. We argue that social positions characterized by powerlessness and by the threat of victimization and exploitation tend to produce paranoia. Powerlessness leads to the belief that important outcomes in one's life are controlled by 
external forces and other persons, rather than by one's own choice and effort. This belief in external control interacts with the threat of victimization or exploitation to produce mistrust, which may then develop into paranoia.' (Mirowsky and Ross, 1983).

The mass globalization, strong hold of capitalism and unequal distribution of wealth has left the whole world in crippling state of imbalance. This has given rise to social inequity and bad governance especially in the developing countries and as a result, the law enforcement and military is ill-equipped to deal with the rising unrest within the country. 'Such places pose what Mike Davis terms 'unique problems of imperial order and social control that conventional geopolitics has barely begun to register: He predicts, soberly, that 'if the point of the war against terrorism is to pursue the enemy into his sociological and cultural labyrinth, then the poor peripheries of developing cities will be the permanent battlefields of the twenty-first century.' (Davis, 2004)

The birth of colonialism, its roots in capitalism and the warfare directly impacted the colonial cities and shifted their urban growth pattern. As explained below, this initiated the new form of military urbanism the effect of which can be seen in the new city planning. In that, effect the constant struggle of the colonial city to regain its land and the resistance of the colonizer and its use of various tools (from religious to political) permanently destabilized the land (colony) for the future generations. This is in-depth analysed by Stephen Graham in his book "Cities under Siege" where he explains the boomerang effect in the West and the birth of new military urbanism. 'The battleground shifted from the open fields to the city walls and further positioned itself within the heart of the city, as a fight for the city itself. If historical siege warfare ended when the envelope of the city was broken and entered, urban warfare started at the point of entering the city.'

Although there had been no studies (so far) which directly prove the relation of terror and the built fabric, especially in the eastern countries where the social structure and hierarchy varies from the west, hence the response of the society to violence and terror may also differ. In this regard this study is not only integral but unique in terms of the its mapping, methodology and analysis. The above-mentioned points (theories/analysis by various writers) act as layers, which may be read as separate but can only be understood in their totality as together they constitute the tangible and intangible fabric of the city. In this regard each point mentioned above has a specific role when understanding the society and its fabric. From globalization to capitalism and its impact on a struggling country, terror can sometime cripple or even degenerate the very fabric of the society. The following attempt is hence imperative as it highlights the force that may change society, laws that govern it and its built environment.

\section{Sectarian Violence}

War in all forms is a terrible thing. It has the power to cause destruction, human losses and sometimes complete annihilation of societies and cultures. Pakistan is not new to the concept of war, yet in the last decade, it has been forced to face war in its deadliest form. Since its formation in 1947, this land has faced many challenges, whether it was the war for freedom or war for its survival (wars of 1966 and 1971) violence has been rising in this land in one form or another. Looking back at the last 67 years, one can easily identify sectarian intolerance as one of the primary culprits for violence and terror in the country. While Sectarian violence (Roberts, 2019) is the oldest form of terror in the country, violence itself has evolved and religious extremism as well as political tension has aided the acceleration of overall volatile atmosphere in the country.

The roots of sectarian violence can be traced to the pre-partition of the sub-continent. By definition, the word sectarian is derived from the word "sect", which means a body of people have diverse views within the same religion (Wilson, 1982). Although the concept of sectarianism is not new, violence due to sectarian conflict has been rising in Pakistan. "Sectarianism reflects the 
deep polarization in a society because of rejectionist approach pursued by various groups belonging to the same religion. When a particular sect feels that it has been excluded from the mainstream religious domain, it adopts a violent course resulting in sectarian violence." (Ahmar, 2010, pp 50-76). Sectarian violence is one of the primary reasons for political, social and religious instability in Pakistan.

Primarily, there are two major religious groups prevailing in Pakistan: Shia and Sunni. Both communities have lived in harmony till certain external forces, such as the Anti-Ahmadi movement which started in February 1953 (Weiss, 1986; Saeed, 2012), the Islamic revolution in Iran, 1979 and the reaction of the Arab world (Pant, 2009; Hussain, 1993) destabilized this coherence and gave birth to current forms of religious intolerance.

\section{Methodology}

The paper starts with an introduction, identification and evolution of violence in the region and country and finally in the city. It then investigates the change in the urban fabric and identification of the various elements added in the fabric of the city. Subsequently, it examines the documentation of the impact of this change due to the addition of urban elements in the social fabric of the city. Following methodology is adopted:

- Documentation of various events and activities through personal accounts and observations on site.

- Photographic documentation through various sources like newspaper articles, official legal/notices by the government etc.

- Mapping the changes in the urban fabric and its impact through diagrams, maps, drawings and photomontage of the site focused for study, over a period of time.

The paper can be divided to the following parts in terms of research methodology and analysis:

- Understanding the evolution of violence in the region and introduction to the new military urbanism ${ }^{i}$ in the city

- Identification of various physical elements introduced in the fabric of the city for the sake of security and protection

- Selection of Mall road as focus area of study

- Impact of these elements on the social fabric of the above-mentioned area.

\section{Limitations}

Lack of theory, detail analysis of post trauma impact on people and the fast-evolving society makes it difficult to understand or even pinpoint a particular lasting effect on the people and communities. With Pakistan being a developing country and Lahore one of its fastest growing city the research had few constraints and limitation when documenting impact of terror on the built and social fabric of the city. Hence, the following analysis becomes one of the first few attempts to comprehend the impact of terror on people and their environment.

\section{Evolution of Sectarian violence to Terrorism}

Statistics (SATP, 2010) show that there has been an increase in sectarian violence resulting in deaths, injuries and overall unrest in the year of 2009-2010 in Punjab. A total of one hundred fifty-two incidents of sectarian violence, including sectarian-related attacks and clashes killed six hundred sixty-three people, which shows a 50\% rise in causalities compared to 2009, and injured another 1,569 people, almost three times higher than in 2009 (PIPS, 2011). This proves that Punjab has been a greater victim of sectarian violence than any other province. 
In the last decade or two, the face of violence has transformed the country. Although it is arguable if the root cause has changed or if it's still sect and religious extremism but the war has intensified in the name of terrorism. Terrorism is the growing cause of unrest and disorder in the world today. The US Department of Defence's, Dictionary of Military (2009) has recently defined terrorism as the calculated use of unlawful violence or threat of unlawful violence to inculcate fear; and is intended to coerce or to intimidate governments or societies in the pursuit of goals generally political, religious, or ideological (Malik, Khawar, Iftikhar, Ilyas, 2010). The acceleration of terrorism in Pakistan is more visible in the aftermath of the 9/11 attacks. Although the existence of Taliban in the neighbouring country of Pakistan cannot be denied, the war in Afghanistan (in response to the September 11 attacks) blurred borders of the two countries. Results can be seen in the formation of Tehrik-e-Taliban (TTP, and many more like it) in Pakistan and the start of a horrendous decade of murder and killing in the country.

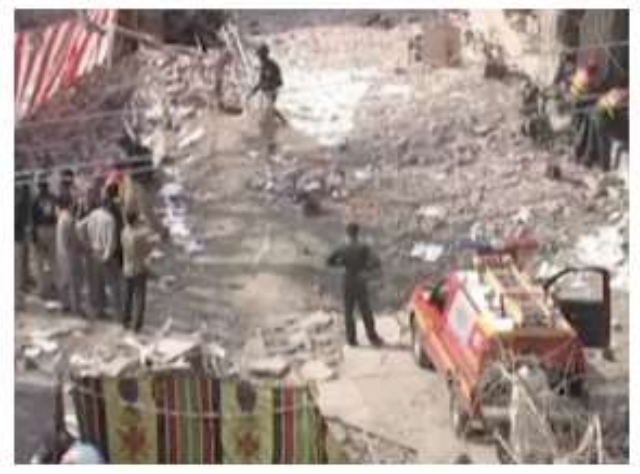

The FIA office, Mall Road

Source: The Express Tribune, 2009

Pakistan has always played an active and crucial role in the "Global war on terror" (GWO) and has been playing it for 12 years now, yet there seems to be no reprieve for the country and its people. Another important factor to consider here is the proximity and the geographical location of the country. It is also because of this that the North Waziristan and KPK regions are the most affected and targeted areas in the country.

In any kind of war, there are casualties. However, for the first time in the history of mankind, we see a kind of war, which is not an external threat (from outside the country or its more evident enemies). Rather, the face of war changes and it looks like it is starting from within (people from within the country fighting and killing each other) and has the capacity to destroy all, causing maximum harm to human lives, city and all-encompassing it. A country like Pakistan which was built on and through extensive bloodshed and post partition has had to heal from the continuous violence of sectarian violence and where the impact of both can still be felt. It has taken its toll on the people and the country to sustain its built but social fabric too due to the recent terrorist's attacks. What starts the war or who is fighting becomes irrelevant at this point because what the city or country is left to deal with is the destruction on mass scale and cost of human lives. The War on Terror has extracted a very high human cost for Pakistan in the last twelve years. On March 27, 2013 intelligence agencies in a report to the Pakistani Supreme Court said that Pakistan has lost 49,000 lives since 2001 (Mehmood, 2013).

\section{Terrorism in Lahore (Punjab)}

'If you want to destabilize Pakistan, an unnamed senior Police Officer in the Province notes, "you have to destabilize Punjab." That, precisely, is the intention of an accelerating and expanding campaign of Islamist extremist terrorism in Pakistan, 
linked intimately to the Taliban - al Qaeda complex, and to the growing movement of the Tehrik-e-Taliban Pakistan ( $\underline{\text { TTP }}$ ), which has turned renegade against its original sponsors and handlers in the Pakistan establishment and Army.'

(Tempest of Terror, August 2009)

Lahore is one of the oldest and major cities of Pakistan, with its origin uncertain, though is traced as earlier as $2^{\text {nd }}$ century, but first being recorded in 982 A.D. It is an important historic city not only because of its built architecture but also because of its role as the political center throughout the history. It is known as the cultural hub of Pakistan. It has historic landmarks, vibrant culture and an opulent urban fabric, having the ability to evolve and change as per the need of time. Post partition the center of Punjab, Lahore has been relatively safe in comparison to other sensitive areas of Pakistan like KPK and Baluchistan. It is also true that where the rest of the country has struggled to maintain peace and stability, Lahore has had the chance to grow and flourish economically, politically and culturally. The past decade has taken its toll on the city of Lahore, impacting the physical as well as the social fabric of the city. Starting in 2006, Lahore saw malicious attacks, which targeted government buildings, and public and religious places. It has been recorded by "CIRCLe" that the attacks in "Punjab account for only $18 \%$ of attacks in the whole of the country, yet in terms of deaths, Punjab is 18 percent of the casualty figure of KPK and 19 percent of the casualty figure of FATA".

Geographically, the terrorist attacks in Lahore slowly spread from the city center towards its periphery, mainly targeting the government, religious or densely populated places, in effect slowly encircling all major public areas, main roads etc.

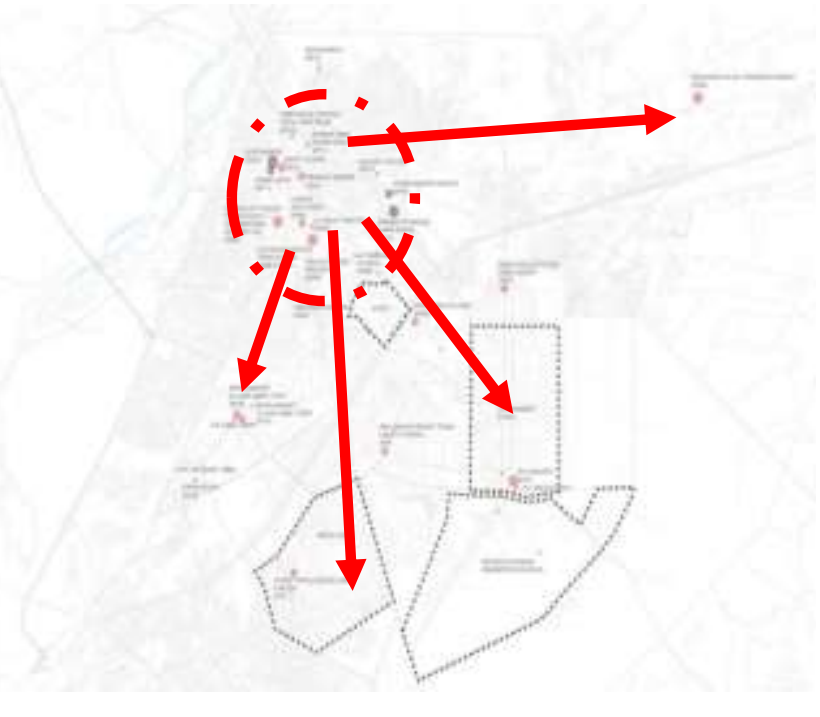

Fig. 1: Spread of Terrorist Attacks in the City Source: Sadia Shirazi, modified by Author

As an immediate response, the government issued notices to schools, colleges, universities and administrative institutes to follow nine steps for their protection. These included the installation of CCTV cameras, storing one month's footage, securing the place with barbed wire, eight-foot high boundary walls, setting up a police post on the roof, proper lighting and hiring security guards from a registered company which is verified by the police (Ali, 2014). Invariably, the first form of defence that is observed is the addition of blockades and check posts, especially 
in the sensitive parts of the city like the Cantonments and around the public/administrative buildings. Later, the following design measures were observed and mapped (By Author) in the public spaces and on individual buildings like:

- Barbwires

- Concrete boundary wall

- Blockades

- Check posts (on streets and around buildings)

- Special forces and security personnel as added reinforcements

As a resident of the city and a user of Mall Road (specifically) it is terrifying to see the number (in terms of attacks and loss of human lives) on paper but it is more terrifying when one tries to understand the psychological and physical impact of these attacks on the city of Lahore. It is crucial to understand that although these attacks took place some years ago and the intensity of the attacks over the years has reduced (reports by government), the people are still facing its aftermath and will keep facing it for the years to come. One of the most basic and obvious results of these attacks is the birth of "fear" and "paranoia" in the society. Although there has been no extensive study in the city or even county to understand the sphere and psychological impact of terrorism on society, studies carried out internationally prove that PTSD and fear (not for the current situation but for any impending attacks) can lead to a dysfunctional society, as also observed in NewYork post 9/11 attacks (Foa, Cahill, Boscarino, Hobfoll, Lahad, McNally, Solomon, 2005).

The map below displays the most crucial time of Lahore from 2008 to 2013 when the suicide bombing and target killing were at its peak, killing approx. half dozen people on an average day. The impact of these years has been catastrophic. The city's social, psychological, economic and physical structures have been damaged and reduced to their bare survival modes. Some major attacks in Lahore include the following (SATP, 2014):

- Attack on the FIA building, Mall road.

- Attack on the naval college, Mall road.

- Attack on the Sri Lankan team visiting Lahore for cricket series, Qaddafi Stadium, Gulberg.

- Attack on Data Darbar, central Lahore.

- Attack on Ahmediya mosque, Gari Shahu etc. (Punjab Assessment). 


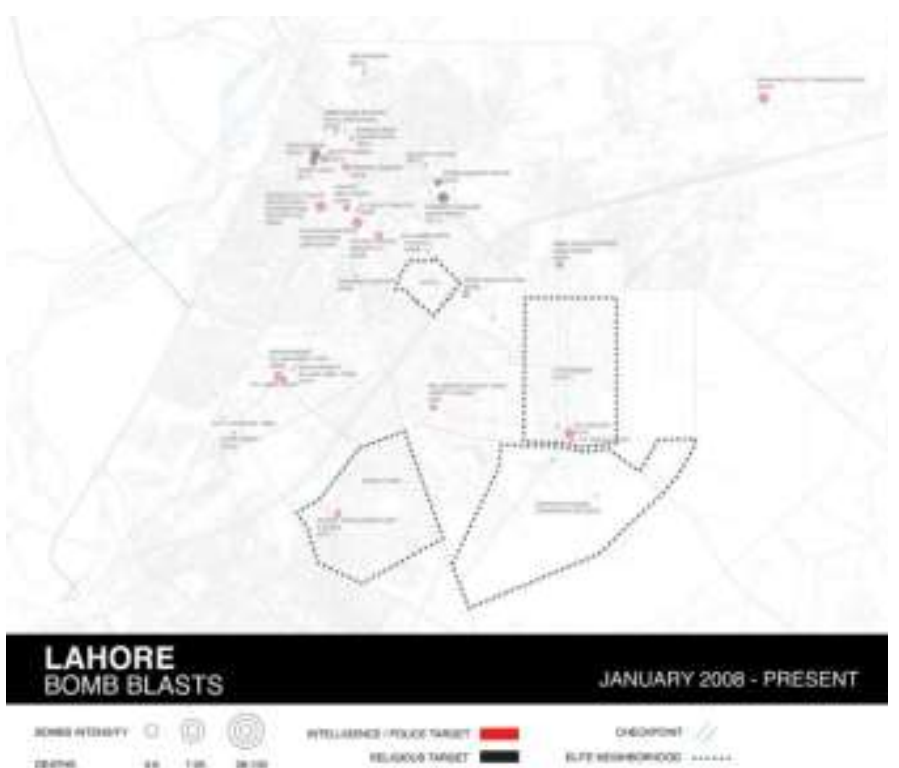

Fig. 2: Terror Attack Areas

Source: Sadia Shirazi, 2012

Looking into more detail, most of these attacks either took place on or around Mall Road, also known as Shahrah-e-Quaid-e-Azam built during the British times to connect the old city of Lahore to the Cantonment of Lahore where British themselves took residence and laid the foundation for an open new city. This road is important as it has some of the most significant government buildings, educational institutes, public buildings and also historic landmarks. It also serves as one of the primary roads forming major connections to the rest of the city. Paralyzing this road would mean paralyzing the whole city. As a result, the impact of the attacks on the Mall road was manifold which indirectly and directly affected the whole city. Attacks on the Mall road could mean multi-faceted impact ranging from major road blocks to shutting down of administrative, public and even educational institutes, damaging the buildings, public spaces as well as long term unsustainability to the economy of the country.

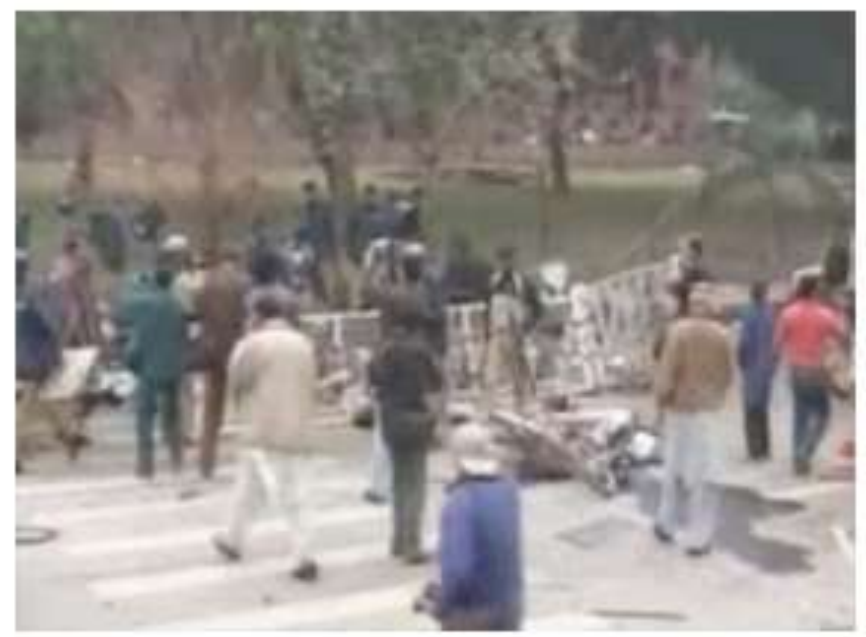

Fig. 3: Suicide bombings at GPO Chowk, Mall Road 


\section{Impact of Terrorism on the City:}

The impact of terrorism is two-fold; direct and indirect. The direct impact can be studied in the form of the destruction it caused, lives lost or harmed and the measures taken to restore city life after the attacks. The indirect impact is more imperceptible, as it slowly takes form in the society and is long lasting thus more dangerous. When fear is at the root of society, it can manifest in two forms. The most obvious and accountable countenance of fear is in the form of physical changes made in the infrastructure of the city. Changes, which have a strong physical presence and can alter the fabric of the city temporarily or permanently. Although most of the times these changes are in the name of security or prevention of any future violence.

\section{Change in the Built Fabric: Concrete Walls:}

An immediate and perpetual impact of the recent events was the construction and extension of existing boundary walls in the city. After the bombings, the government announced that all walls of public building be increased from $6 \mathrm{ft}$ to $8 \mathrm{ft}$ (Public notices given to all public and private buildings). Even places like public buildings and parks or entertainment centers were forced to enclose themselves behind high walls and barbwires to ensure the safety of the place and the people within. The city of Lahore changed overnight. Once an open vibrant city, now is a hodgepodge of walls and metal wires. Result are most evident on the Mall road where these walls have drastically changed the image of the whole city. Walking on the Mall road today, one has no view of the extensive British gardens in front of the buildings or the historic buildings which were once the landmark on the road (Visual observation by Author).

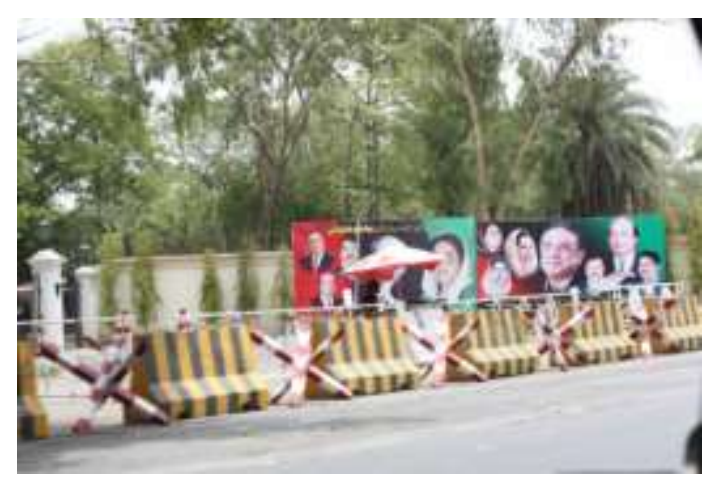

Fig. 4: Governor House, Mall road. (2011) Source: The Funambulist Magazine

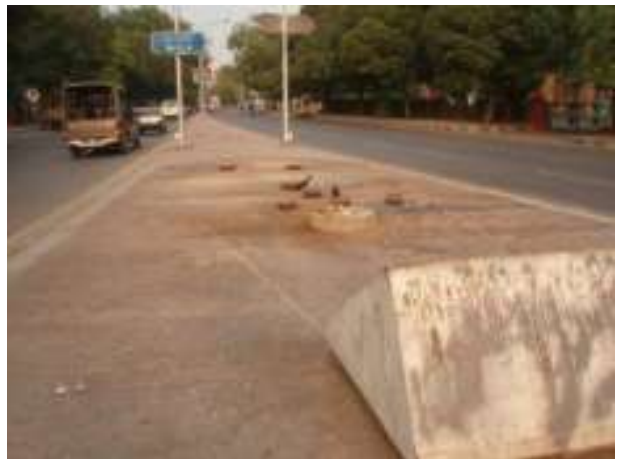

Fig. 5: Mall Road, 2007 Source: Author

These walls are the first form of permanent change in the fabric of the city; superimposed on one of the oldest roads of the city, it sets new parameters for the future design and direction of the city. This has changed the character of the road as originally most of the buildings on the Mall road were built around extensive gardens with no or low railing marking the boundaries of the road and building space. 


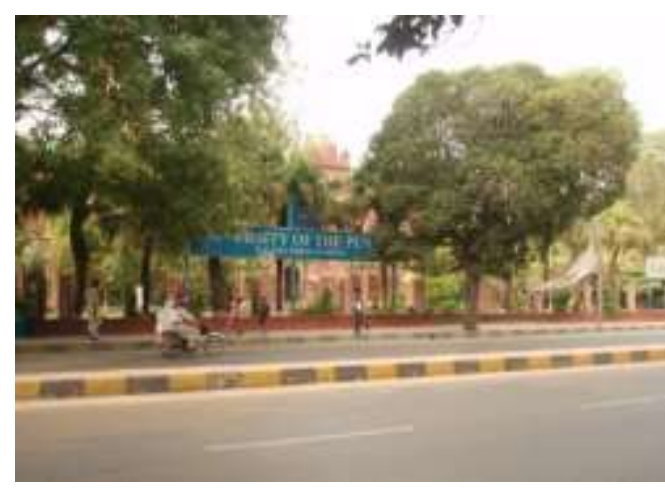

Fig. 6: Punjab University, Mall road, Low Height Fence

Source: Author, 2007

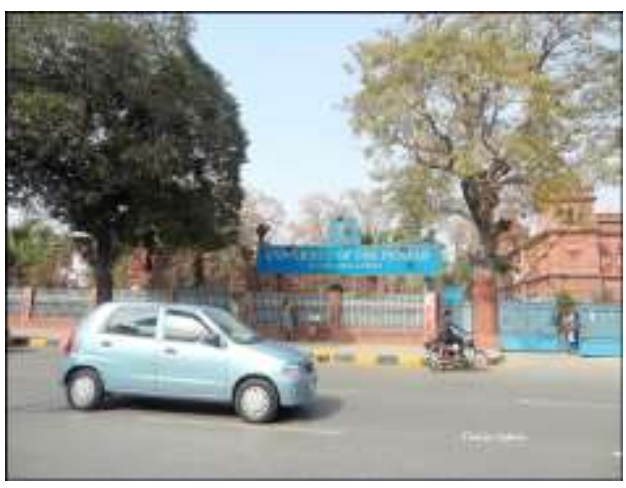

Fig. 7: Punjab University, Mall Road Source: The Funambulist Magazine, 2012

\section{Check posts and Blockades:}

Another important change witnessed throughout the city is the erection of check-posts (military, police or even personnel) throughout the city. Essentially, check posts are the temporary structures on major roads or junctions of the city, at the entrance of buildings or residential societies to ensure safety. These check-points have the uncanny ability to appear, dis-appear or change overnight without warning. Every morning, an average Lahori has to pass through (in some cases) numerous check points to go to their work places or schools etc. In some cases, these check points have caused such drastic traffic blocks causing delays and sometimes accidents. In some parts of the city like Lahore Cantt (Cantonment) these check points have been made a permanent part of the infrastructure, drastically altering the fabric of the area by changing the traffic routes or road patterns and majorly impacting the traffic and road networks.

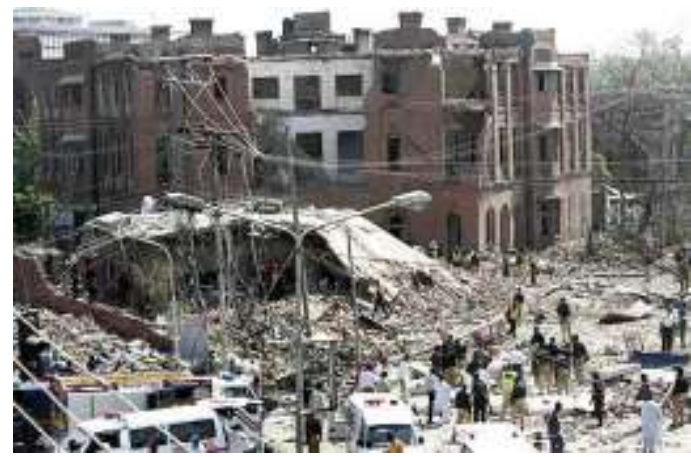

Fig. 8: Terrorist attack on FIA headquarter, Lahore

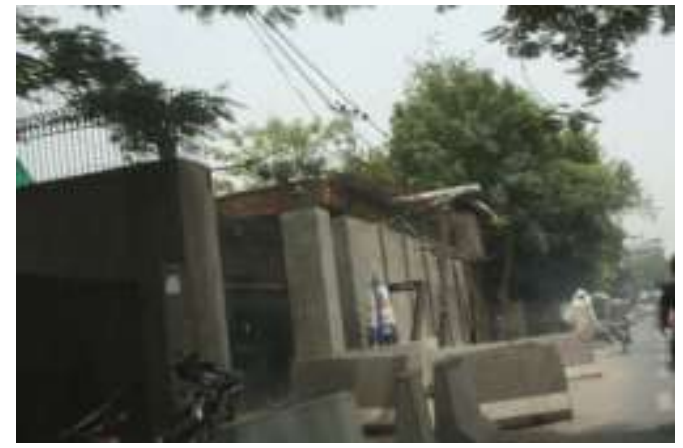

Fig. 9: FIA Headquarter, Temple Road Source: The Funambulist Magazine, 2012

Source: Rediff News, 2009

\section{Addition of Special Forces and security personnel:}

Another layer in the name of security added to the city is that of special forces (more visible on road check posts) and security personnel (added to individual buildings and public places). A more fluid layer, it ends up having the utmost authority over the city, its movements and the people. Most of the time, security forces are seen defending the check points of Cantonment area or wherever the government seems desired. In other words, these forces can appear over night at any part of city and have the authority to stop or barricade movement to that area of the city. Security personnel dedicated to a specific building are more constant as they are restricted to the 
entrance to buildings or private/public spaces; although they also retain the authority to restrict movement and prohibit entrance.

\section{Mapping Mall Road from Lower Mall to Tollinton Market:}

A good case in point will be the evaluation of the area of the Mall road again. At a social level, the road has witnessed many changes. Mall road is famous for many things but here the focus is on the specific section of the road where three educational institutes the Punjab University (PU), Government College (GC) and National College of Arts (NCA)) and one of the oldest markets (Anarkali Bazar) of Lahore is situated. A decade ago, this area was the hub of all cultural activities, students thrived in it and also took part earnestly. Two of Lahore's most famous Colleges (PU, \&NCA) stand opposite to each other on this road but instead of the road acting as a barrier between the two, one finds it used to form a bridge between the two and encouraged students to interact and socialize. The road became a meeting point and the footpaths could be seen as an extension of the student activity taking place in the building that spilled onto the footpaths making the road and the footpath an essential part of the building itself. Post terrorist attacks and threats witnessed a completely different scenario. The creation of walls not only created a physical and visual barrier but also socially dissected the footpaths from all activities of the buildings. Result was barren footpaths and an alienated road.

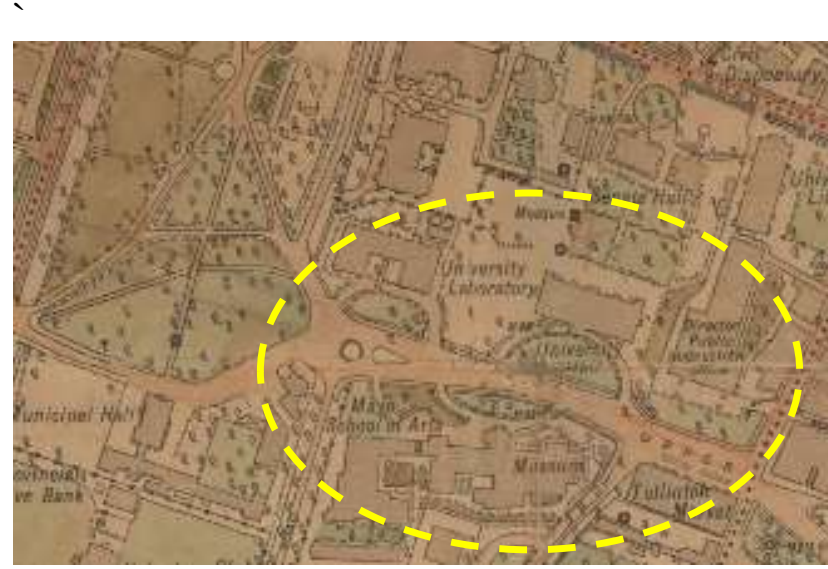

Fig. 10: Map: 1924

National College of Art, Punjab University, Government College and Anarkali.

Source: Archives NCA

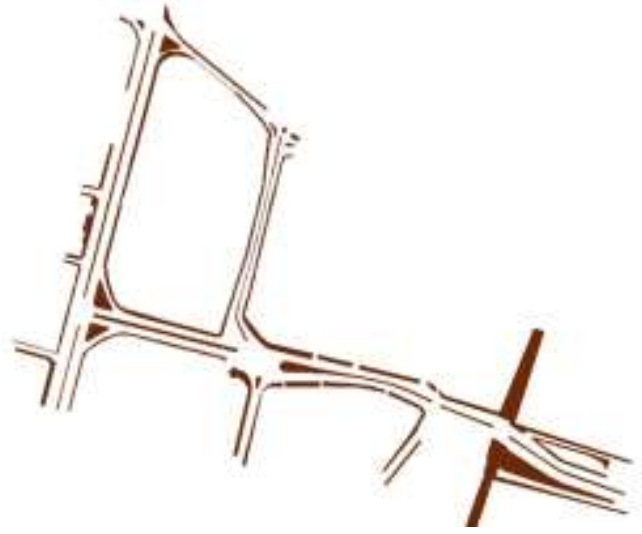

Footpaths, Mall Road Source: Author

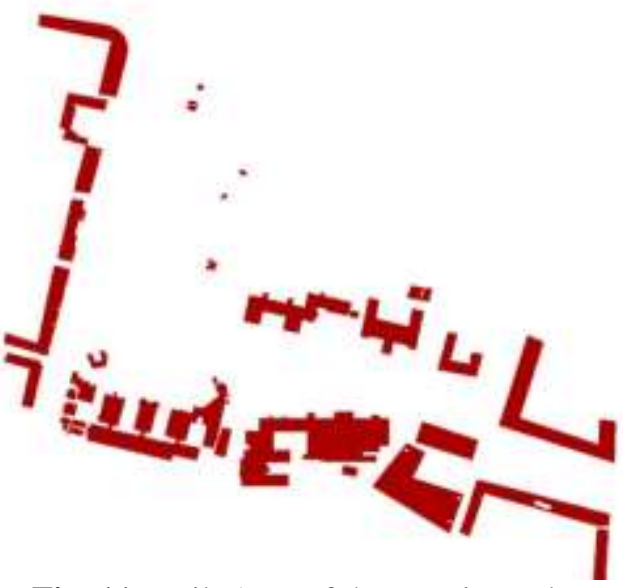

Fig. 11: Built Area of the case in study Source: Author

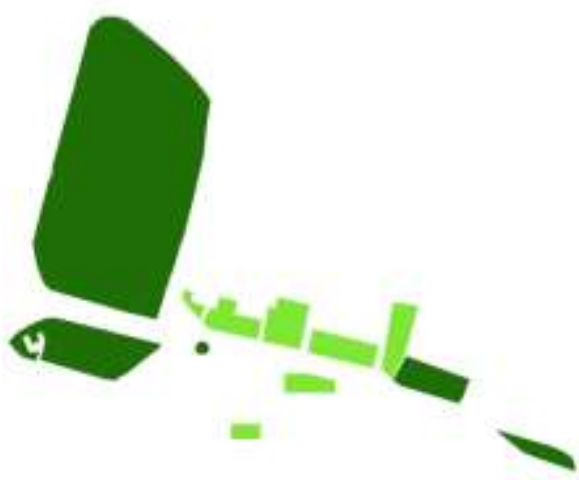

Green Areas, Mall Road Source: Author 


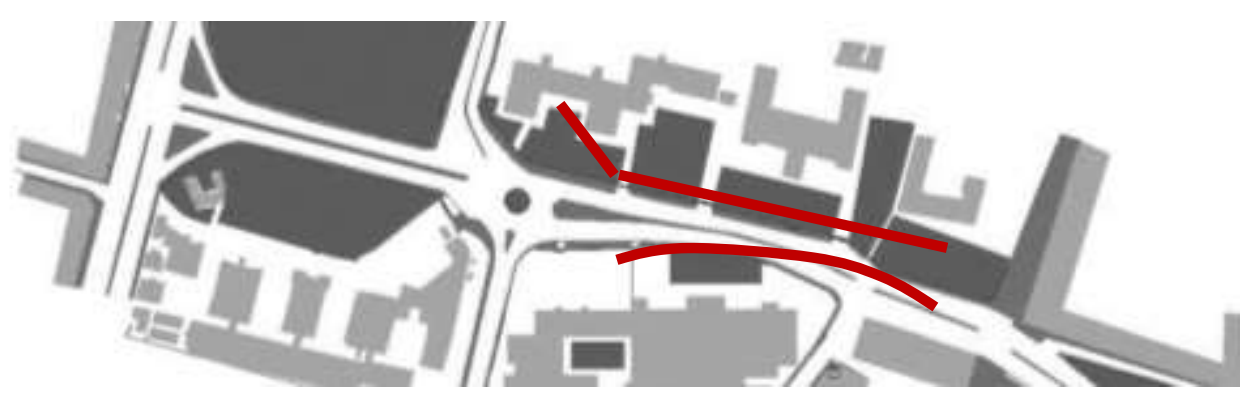

Fig 13: Mapping the addition of walls and barriers, Mall Road Source: Author

The maps above show firstly an older map of the selected area for study highlighted. The map is crucial as it maps the first attempt to lay down the pattern on which the city was being designed. Essentially, the urban fabric was designed around extensive gardens as forefront to buildings, deep footpath as buffer between roads and gardens and ample areas for green plantation to encourage pedestrian movement and activities. This intention can be further understood by the figure ground maps of the area shown above with mapping of built areas, green spaces and elaborate footpaths. The last map marks the high walls, barriers and check posts superimposed on the fabric for added security.

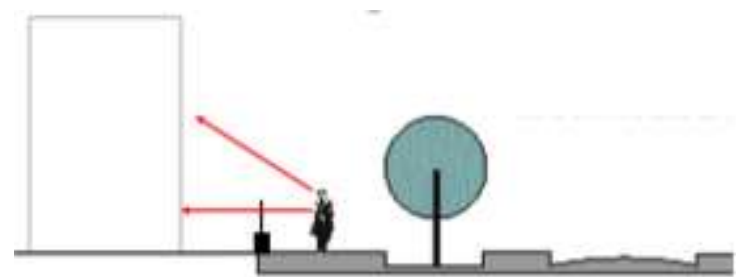

Fig. 14: Low Height Walls and Fence, Mall Road Source: Author

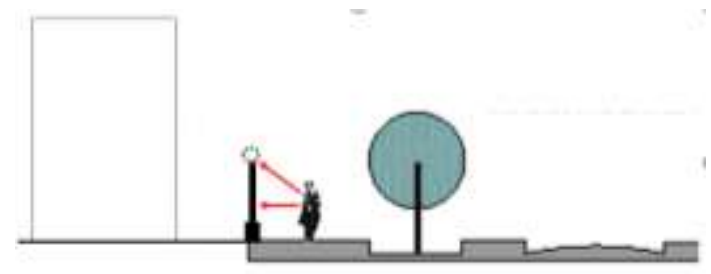

Fig. 15: Present High Walls and Barbwires, Mall Road Source: Author

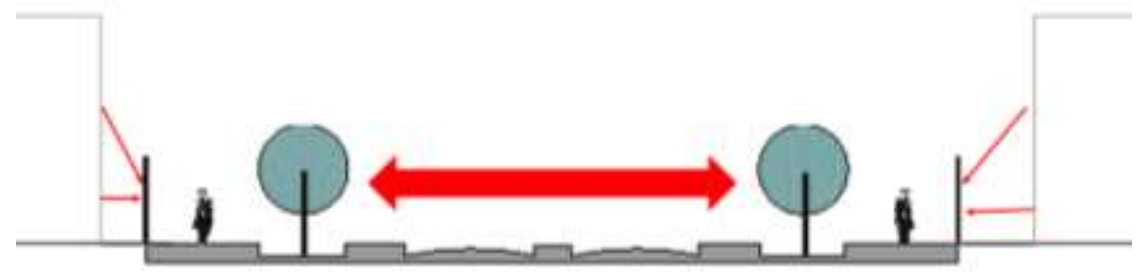

Fig. 16: Present Visual Discontinuity, Mall Road Source: Author 


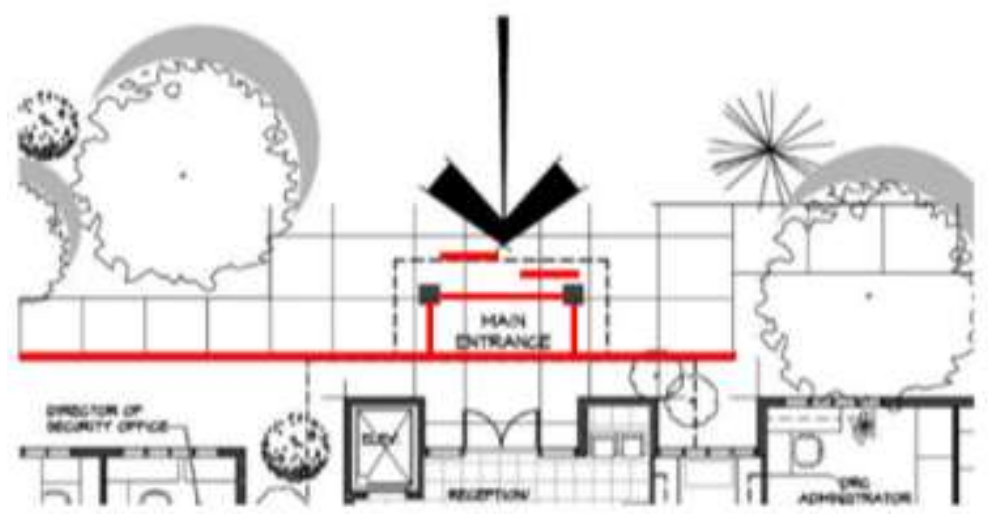

Fig. 17: Typical Form of Blockades Source: Author

In fig 6, following is observed:

- Building Security at entrance at the following levels marked in red in the above drawing:

- Bollards at interval to slow the car, pushing the entrance several feet from building boundary

- Automatic/manual barrier to further restrict entrance

- Security personnel to monitor the movement

Moreover, another essential change was brought to the entrances of the buildings by adding barriers and check points and where available, entrances all together were moved to the back of buildings further isolating the buildings and the road. Mall road is considered a sensitive area and most of the times, is on high alert. This air of threat and insecurity has further deteriorated the character, culture and atmosphere of the area. In National College of Arts, it was common for art students to interact, mingle and welcome everyone a decade ago. Now, it is discouraged by the parents, friends and the university staff itself to even leave the sanctuary of the walls of the campus similar is true for other educational institutes in the area.

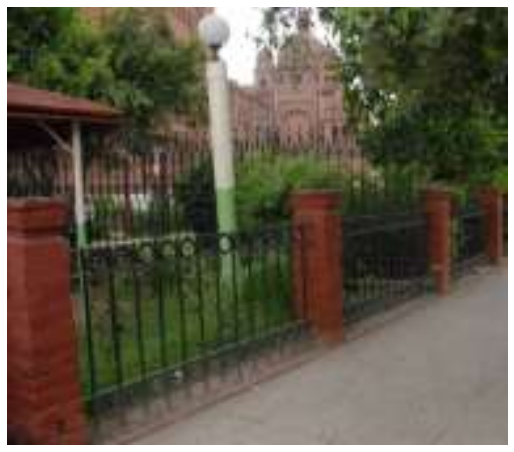

Fig. 18: Fence of Lahore Museum, 2009 Source: Author

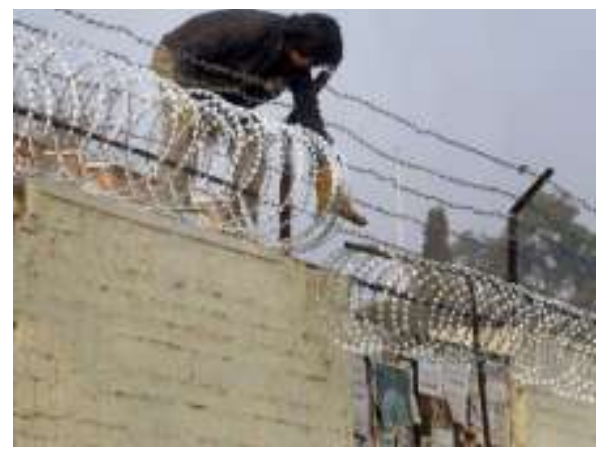

Fig. 19: Concrete walls and barb wires, 2015 Source: The Express Tribune

War on terror has taught some valuable lessons to the society. Awareness of one's surroundings and better preparation for any emergency is one of them. Over the years, where fear and frustration in society has mounted, a certain level of nationalism has also risen in people, especially in neighbourhoods' people are now watchful of their neighbours and friends and any strange unfamiliar face is immediately pointed out and reported to the authorities. This has brought communities closer and more empathetic to each other. Another good example arising from the 
fear is the use of various social and cultural tools to fight terror e.g. the use of graffiti in public spaces, walls and parks to encourage united front, which in result has brought the communities together and also encouraged the artistic endeavours.

Government has also been proactive in this case and should be appreciated. Rescue teams like 1122 in Lahore is one of the best rescue teams in the country and has a fast-growing network. Sense of patriotism and a rise in sense of ownership has intensified in the people of Lahore especially in the younger generation. These youngsters are usually the first to lend a helping hand in any emergency and the first to protest in the face of any injustice. In effect the establishment of better systems to secure the society and its people has been proactively worked on by the government.

City is a fact in time (Lynch, 2001). It has the capacity to absorb all and reflect back all that has happened within it through its people and spaces. Lahore is a unique city in term of its dynamic culture, rich history and flourishing economy, and it had been devastating for the people of Lahore to see the culture mutating, history laden with bloodshed and the economy crippled. In retrospect, the city has been a victim of a brutal war, a war that has left many bruises on its fabric physically and mentally. The face of war is ever changing. However, importantly, this leaves some fundamental questions for the society and its people to ponder. Like how to keep safe yet preserving the culture and essence of the society too? Or how to creatively build into the fabric of the city, design elements to secure without changing the traditions or patterns of livings. ICan these design elements which are used to combat fear and terror be made part of the society without actually contributing to the environment of fear? There may be many more questions like these, which can help better shape the city and the lives of its people, keeping their lives safe without essentially harming the core and heart of its society.

\section{Conclusions:}

Conclusion can be summarized as follows:

- This paper is a preliminary attempt in understanding the changing built fabric of the city in response to certain events such as the terrorist attacks during the year 2009-2012. This study is important as it marks an important shift in the way city moved, observed and interacted. Therefore, through mapping the research will mark the first stage of this shift.

- As there has been no concrete investigation done to map the sociological or psychological impact of terrorist attacks on the cities of Global South, hence the built changes (mapped in the paper) lack the clinical support required from such data.

- A society constantly suffering or in fear of war is vulnerable and is in a relentless state of paranoia and terror. As mentioned above this fear has permanently changed the way people build, interact and communicate amongst each other. Hence, a layer of fear as part of its historic process has been added to the fabric of the city which may further inform and guide the future generations.

- The lack of appropriate laws and policies leave the society ill-equipped to deal with this kind of terroristic war. A war that happens right on their footsteps quickly degenerates and leaves the society in a constant state of fear. Hence, people find quick remedies like building higher walls and more armed guards which may relieve immediate tension but does not solve the bigger problem at the society level. The government needs to have a proactive role in not only prevention but creating emergency protocol to respond to any future crisis.

- Better understanding of built fabric and the society attached (especially in the context of this region) to it is required to secure the city for future generations. In the present scenario the elements added to the city create further paranoia instead of a secure environment. 


\section{References:}

Ahmar. M, (2010) "Sectarian conflict in Pakistan: some lessons from the Irish experience." IPRI Journal X no.1: 50-76.

Ali. F, (2014) Limited responsibility: Police ask minorities to secure themselves. The Express Tribune. [online] Available at: https://tribune.com.pk/story/691476/limitedresponsibility-police-ask-minorities-to-secure-themselves/.

Center for Innovative Research, Collaboration and Learning. n.d. Pakistan Since 9/11: A Statistical Report of a Decade of The War on Terror. [online] Available at: <http://www.circle.org.pk/.

Crossette, B. Nytimes.com. (2020) Lahore, A Survivor with a Bittersweet History. [online] Available at: <https://www.nytimes.com/1981/06/14/travel/lahore-a-survivor-with-abittersweet-history.html.

Davis. M, (2004) The Urbanization of Empire. Social Text, 22(4), pp.9-15.

Foa, E., Cahill, S., Boscarino, J., Hobfoll, S., Lahad, M., McNally, R. and Solomon, Z., 2005. Social, Psychological, and Psychiatric Interventions Following Terrorist Attacks: Recommendations for Practice and Research. Neuropsychopharmacology, 30(10), pp.1806-1817.

Foucault, M. and Ewald, F. (2008) Society must be defended. London: Penguin.

Graham, S. (2014) Cities Under Siege: Verso.

Lynch, K, 2001. Good City Form. Cambridge, Mass: MIT Press.

Malik. F, Khawar. R, Iftikhar. R and Ilyas. R. (2010) Development of Terrorism Impact Scale: Initial validity and reliability analysis. Pakistan Journal of Social and Clinical Psychology. 8. 91-118. 10.1037/t44059-000.

Mehmood. R. (2013) Walking Through Terror and Tragedy in Lahore | The Express Tribune. [online] Available at: <http://tribune.com.pk/story/487447/walking-through-terror-andtragedy-in-lahore.

Mirowsky, J. and Ross, C. (1983) Paranoia and the Structure of Powerlessness. American Sociological Review, 48(2), p.228.

n.d. (2013) Pakistani Victims: War on Terror Toll Put at 49,000 | The Express Tribune. [online] Available at: <http://tribune.com.pk/story/527016/pakistani-victims-war-on-terror-tollput-at-49000.

Shirazi, S, (2012) "City, Space, Power: Lahore's Architecture of In/Security". Retrieved from https://thefunambulist.net/editorials/guest-writers-essays-36-city-space-power-lahoresarchitecture-of-insecurity-by-sadia-shirazi

Satp.org. (2014) Punjab Assessment - 2017. [online] Available at: $<$ http://www.satp.org/satporgtp/countries/pakistan/punjab/index.html.

Weizman. E, Misselwitz. P, (2003) 'Military Operations as Urban Planning', Mute Magazine. 